\section{Nocturnal gastro-oesophageal reflux, asthma and symptoms of OSA: a longitudinal, general population study}

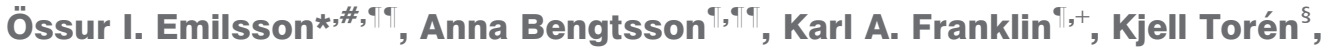 \\ Bryndís Benediktsdóttir*\#, Amir Farkhooy ${ }^{\dagger}$, Joost Weyler**, Sandra Dom**, \\ Wilfried De Backer ${ }^{\# \#}$, Thorarinn Gislason*,\# and Christer Janson ${ }^{f}$
}

ABSTRACT: Nocturnal gastro-oesophageal reflux (nGOR) is associated with asthma and obstructive sleep apnoea (OSA). Our aim was to investigate whether nGOR is a risk factor for onset of asthma and onset of respiratory and OSA symptoms in a prospective population-based study.

We invited 2640 subjects from Iceland, Sweden and Belgium for two evaluations over a 9-year interval. They participated in structured interviews, answered questionnaires, and underwent spirometries and methacholine challenge testing. nGOR was defined by reported symptoms.

Subjects with persistent $n G O R(n=123)$ had an independent increased risk of new asthma at follow-up (OR 2.3, 95\% Cl 1.1-4.9). Persistent nGOR was independently related to onset of respiratory symptoms (OR 3.0, 95\% $\mathrm{Cl} 1.6-5.6)$. The risk of developing symptoms of OSA was increased in subjects with new and persistent nGOR (OR 2.2, 95\% $\mathrm{Cl} 1.3-1.6$, and OR 2.0,95\% Cl 1.0-3.7, respectively). No significant association was found between $\mathrm{nGOR}$ and lung function or bronchial responsiveness.

Persistent symptoms of nGOR contribute to the development of asthma and respiratory symptoms. New onset of OSA symptoms is higher among subjects with symptoms of nGOR. These findings provide evidence that nGOR may play a role in the genesis of respiratory symptoms and diseases.

KEYWORDS: Asthma, gastro-oesophageal reflux, lung function, nocturnal, obstructive sleep apnoea

$\mathrm{H}$ eartburn is one of the most common symptoms experienced in the western world. It is usually caused by gastrooesophageal reflux (GOR), and affects $12 \%$ of the adult population on a weekly basis [1]. Asthma is also a common disease with a prevalence of $\sim 5 \%$ [2]. Co-occurrence exists between GOR and airway symptoms, and asthma and symptoms related to obstructive sleep apnoea (OSA) [3, 4]. Additionally, subjects with GOR disease have been reported to have significantly lowered forced expiratory volume in $1 \mathrm{~s}$ (FEV1) and peak expiratory flow [5].

GOR treatment has been shown to have a significant effect on pulmonary illnesses. KILJANDER et al. [6] observed that esomeprazole $40 \mathrm{mg}$ twice daily during 26 weeks improved pulmonary function and asthma-related quality of life in asthmatic patients with GOR. This finding has been supported by others, but is not entirely consistent in the literature $[7,8]$.
Recently, nocturnal GOR (nGOR) has become of special interest as a distinct clinical entity. It is considered to be more harmful than daytime GOR, and has a greater risk of leading to respiratory complications $[9,10]$. OSA patients are also more likely to have nGOR, which by itself causes arousals during sleep and can therefore cause even more sleep impairment [11, 12]. However, all epidemiological studies on these associations have been cross-sectional and to our knowledge there is no prospective study investigating whether nGOR induces respiratory disorders, including asthma and OSA.

Our aim was to investigate in a 9-year prospective population-based study whether nGOR is a risk factor for the onset of respiratory symptoms in relation to asthma and symptoms of OSA.

\section{METHODS}

The present study is an international, populationbased cohort study, a 9-year prospective follow-up
AFFILIATIONS

*Faculty of Medicine, University of Iceland, Landspitali University Hospital, Reykjavik, and

\#Dept of Respiratory Medicine and Sleep, Landspitali University Hospital, Reykjavik, Iceland. "Dept of Respiratory Medicine, Umeå University, Umeå

'Dept of Surgery, Umeå University, Umeå,

${ }^{\text {s }}$ Section of Occupational and Environmental Medicine, Institute of Medicine, University of Gothenburg, Gothenburg, and

${ }^{f}$ Dept of Respiratory Medicine and Allergology, Uppsala University, Uppsala, Sweden

**Dept of Epidemiology and Social Medicine, University of Antwerp, Antwerp, and

\#\#Dept of Pulmonary Medicine, University of Antwerp, Antwerp, Belgium.

"Joint first authors.

CORRESPONDENCE

Ö.I. Emilsson

Faculty of Medicine

University of Iceland

Vatnsmýrarvegi 16

101 Reykjavik

Iceland

E-mail: ossuri@landspitali.is

Received:

March 282012

Accepted after revision: Sept 172012

First published online:

Sept 272012 
of 2640 randomly selected subjects from Reykjavik (Iceland), Gothenburg and Uppsala (Sweden) and Antwerp (Belgium), who participated in the European Community Respiratory Health Survey (ECRHS) [3, 13]. All participating subjects in ECRHS I were invited for ECRHS II. They participated in a structured interview, answered questionnaires, underwent spirometry, methacholine challenge studies, measurements of height and weight, and gave blood samples for analyses of specific and total immunoglobulin (Ig)E. The study was approved by the local ethics committees in all participating centres (National Bioethics Committee of Iceland: VSNb2010090010/03.1; The Regional Ethical Committee of Uppsala University: Ups 99-313; The Advisory Committee for Medical Ethics of the University of Antwerp, Belgium: 99/021).

The same definition of nGOR was used both at baseline and follow-up 9 years later. nGOR was defined based on the occurrence of heartburn or belching after lying down [3]. All subjects reporting nocturnal reflux symptoms (from less than once a week to almost every night) were classified as having nGOR. The subjects were divided into four groups based on their answer at baseline and follow-up: never nGOR, nGOR at baseline, nGOR at follow-up and persistent nGOR (nGOR at both baseline and follow-up). The participants were asked specifically about usage of medications for acid reflux in the preceding month.

Subjects were considered to have asthma if they reported having been diagnosed with asthma by a physician plus having asthma-related symptoms in the last 12 months [14]. Questions with yes/no answers were posed about the following respiratory symptoms at any time in the last 12 months: wheezing, nocturnal chest tightness, shortness of breath at rest and after exercise, nocturnal shortness of breath and nocturnal cough. Subjects who had had any of these respiratory symptoms in the last 12 months were additionally classified as having "any respiratory symptom". Participants defined with asthma, or reporting a particular symptom at follow-up but not at baseline, were defined as having an onset of asthma or respiratory symptoms during the study period [15].

Symptoms of OSA were estimated by a questionnaire and defined as self-reported snoring, apnoeas or daytime sleepiness. The same questions were used at baseline and follow-up. Those reporting observed snoring or daytime sleepiness more than twice a week, or observed apnoeas once a week or more, were considered to have the corresponding symptom. Those with any of the above-mentioned symptoms were additionally classified as having "any OSA symptom". For a more OSAspecific analysis of these symptoms, those with new snoring and/or apnoea plus new daytime sleepiness were also analysed together.

In the follow-up, participants also answered the Epworth Sleepiness Scale (ESS) [16]. A score of $\geqslant 10$ was considered as significant daytime sleepiness. ESS was not used when analysing onset of OSA symptoms as it was not available at baseline.

Smoking history was investigated by asking subjects at baseline and follow-up whether they were current smokers, ex-smokers or never-smokers. Based on this information the subjects were classified into never-smoker, ex-smoker, quitter and smoker groups.
The maximum FEV1 and maximum forced vital capacity (FVC) from five technically acceptable blows were determined [17]. FEV1/FVC was calculated from these maximum values. Predicted values for FEV1, FVC and FEV1/FVC were calculated on the basis of the European Coal and Steel Union reference values [18]. A change in lung function was calculated as the change per year in percentage of predicted values between the two studies.

A methacholine challenge was carried out using a dosimeter (Mefar, Brescia, Italy). The starting dose was $0.002 \mathrm{mg}$ followed by several dose steps up to an accumulated dose of $1 \mathrm{mg}$. A change in bronchial responsiveness was expressed as a change in slope per year of follow-up [19]. Bronchial hyperresponsiveness (BHR) was defined as a fall in FEV1 of $\geqslant 20 \%$ following an accumulated dose of $1 \mathrm{mg}$ methacholine [20].

Blood samples were collected for the measurement of total and specific serum IgE using the Pharmacia CAP System (Pharmacia Diagnostics, Uppsala, Sweden). Specific IgE was measured at baseline against Dermatophagoides pteronyssinus, cat, birch, Timothy grass and Cladosporium herbarum. The detection of specific IgE of $\geqslant 0.35 \mathrm{kU} \cdot \mathrm{L}^{-1}$ was used as a definition of sensitisation to a specific allergen. Atopy was defined as sensitisation to at least one of the investigated allergens.

\section{Statistical analysis}

All statistics were calculated with STATA 11.0 software, version intercooled (Stata Corporation, College Station, TX, USA). Associations were analysed by Chi-squared test and linear and logistic regressions. Adjusted calculations were performed by adjusting for sex, age, location, smoking history at follow-up, body mass index (BMI) at baseline and change in BMI. A pvalue of $<0.05$ was considered statistically significant.

\section{RESULTS}

A total of 1761 subjects (response rate $66.7 \%$ ) were investigated at baseline and followed up after 9 years (fig. 1). The characteristics of the participants are presented in table 1 . Subjects with new or persistent nGOR had a higher baseline BMI $(\mathrm{p}<0.001)$ and used more anti-reflux medication; those with persistent nGOR were slightly older. No significant differences were found regarding sex, change in BMI, smoking or atopy.

\section{Asthma and respiratory symptoms}

Subjects with persistent nGOR had significantly more newonset asthma than subjects without nGOR (table 2). This association remained statistically significant after adjusting for sex, age, location, follow-up time, smoking history, BMI at baseline and change in BMI (adjusted OR 2.33, 95\% CI 1.124.87) (fig. 2). Persistent nGOR was also independently related to new onset of daytime and nocturnal respiratory symptoms, such as wheezing with breathlessness, chest tightness and cough (fig. 3). Taken together, the adjusted risk for developing any respiratory symptom during the study period was significantly higher among subjects with persistent nGOR than subjects without nGOR (table 3).

\section{OSA symptoms}

New onset of OSA symptoms was significantly more common in subjects with new or persistent nGOR (table 4). For all symptoms except daytime sleepiness, new onset was most 


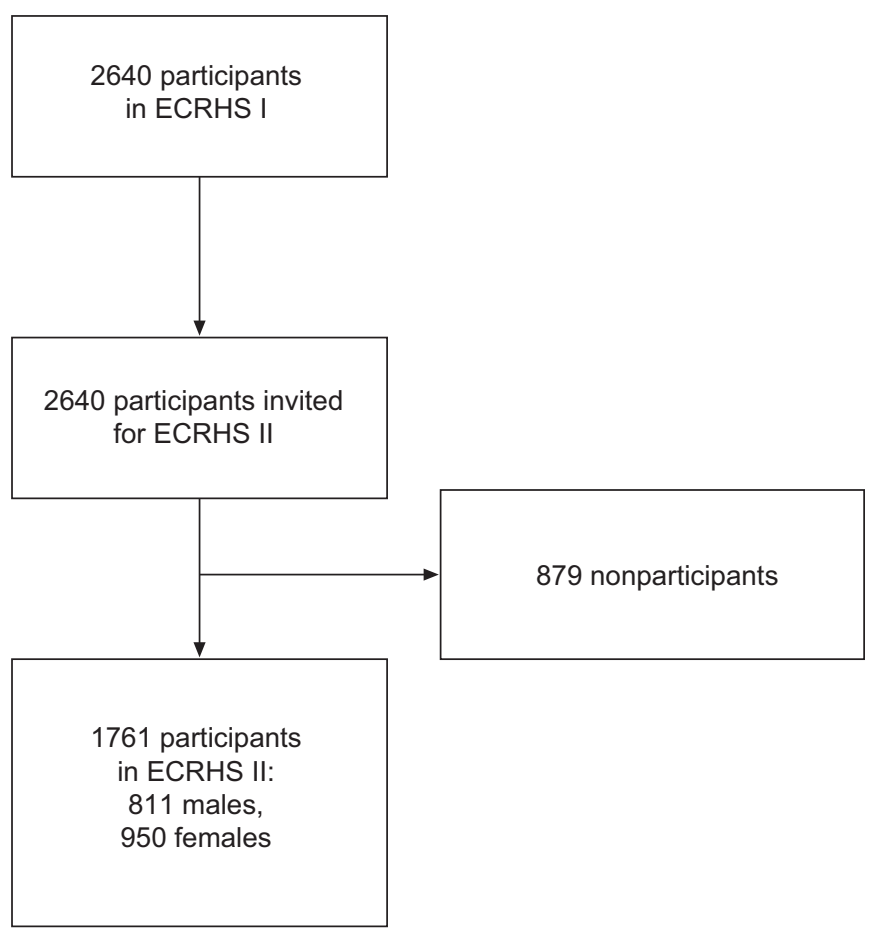

FIGURE 1. A flow diagram showing selection of cases for the European Community Respiratory Health Survey (ECRHS) II.

common among subjects with persistent nGOR, albeit only a little higher than among subjects with new nGOR. The combination of new snoring and/or apnoeas together with new daytime sleepiness was most common among subjects with persistent nGOR. Subjects with former nGOR had a similar risk of new onset of OSA symptoms as subjects without nGOR. These associations remained significant after adjusting for sex, age, location, follow-up time, smoking history, BMI at baseline and change in BMI (table 3). Those with new or persistent nGOR had a higher ESS score than subjects without nGOR (table 4 and fig. 4), and this remained significant after adjusting for sex, age, location, follow-up time, smoking history, BMI at baseline and change in BMI.

\section{Spirometry and bronchial hyperresponsiveness}

On follow-up after 9 years, spirometry was performed in 1417 persons and methacholine challenge in 976 persons. No significant association was found between nGOR status and change in FEV1, FVC or FEV1/FVC (table 5). The prevalence of new onset of BHR during the study period was, however, significantly higher in subjects with persistent nGOR (table 5). This association was not statistically significant after adjusting for age, sex, location, follow-up time, smoking history, BMI at baseline and change in BMI (adjusted OR 2.01, 95\% CI 0.81-4.96).

\section{Interactions}

Interaction analyses were performed while simultaneously adjusting for location, age, sex, follow-up time, smoking history, baseline BMI and change in BMI. The association between new nGOR and new OSA symptoms was stronger among males than females (OR 5.6, 95\% CI 1.9-16.6 versus OR $1.4,95 \%$ CI 0.8-2.6; pinteraction $=0.03$ ). The association between persistent nGOR and new respiratory symptoms was stronger among females than males (OR 21.6, 95\% CI 2.8-163.2 versus OR 1.7, 95\% CI 0.8-3.6; pinteraction=0.02). No other significant interactions in the associations between nGOR status and respiratory symptoms, lung function or OSA symptoms were found for atopy, obesity, smoking, BMI, location or sex.

Among those with new nGOR, those who were using antireflux medication had a significantly smaller decrease in FVC than those who were not (coefficient $0.33,95 \%$ CI $0.01-0.65$ versus coefficient -0.19 , 95\% CI $-0.38-0.01$; pinteraction $=0.03$ ). There were no significant differences in change in FEV1, BHR and prevalence of onset of asthma, respiratory or OSA symptoms between anti-reflux medicating or nonmedicating subjects with persistent nGOR (data not shown).

\section{Participants and nonparticipants}

Participants at follow-up were less likely to be smokers at baseline (31.8 versus $44.8 \%$; $<0.001$ ) and had a slightly higher

TABLE 1 Population characteristics in relation to nocturnal gastro-oesophageal reflux (nGOR)

\begin{tabular}{|c|c|c|c|c|c|c|c|}
\hline & Never nGOR & Former nGOR & p-value ${ }^{\#}$ & New nGOR & p-value ${ }^{\#}$ & Persistent nGOR & p-value ${ }^{\#}$ \\
\hline Subjects n & 1298 & 139 & & 201 & & 123 & \\
\hline Male & 46.1 & 46.0 & 0.99 & 42.8 & 0.39 & 51.2 & 0.28 \\
\hline Baseline BMI $\mathbf{k g} \cdot \mathrm{m}^{-2}$ & $23.3 \pm 3.3$ & $23.9 \pm 3.3$ & 0.07 & $24.0 \pm 3.4$ & 0.02 & $25.4 \pm 4.4$ & $<0.001$ \\
\hline Change in BMI $\mathrm{kg} \cdot \mathrm{m}^{-2}$ & $1.9 \pm 2.2$ & $1.5 \pm 2.4$ & 0.14 & $2.1 \pm 2.1$ & 0.25 & $2.1 \pm 2.7$ & 0.38 \\
\hline Smoking & & & 0.05 & & 0.87 & & 0.22 \\
\hline Never & 44.2 & 36.7 & & 47.2 & & 36.1 & \\
\hline Ex-smoker & 21.6 & 17.3 & & 20.6 & & 27.9 & \\
\hline Quitter & 12.9 & 17.3 & & 12.6 & & 11.5 & \\
\hline Smoker & 21.3 & 28.8 & & 19.6 & & 24.6 & \\
\hline
\end{tabular}

Data are presented as mean \pm SD or \%, unless otherwise stated. BMI: body mass index. "* calculated with "never nGOR" as a reference group; ": any use in the month before follow-up. Bold represents statistical significance. 
TABLE 2 Respiratory symptoms with onset during study period in relation to nocturnal gastro-oesophageal reflux (nGOR)

\begin{tabular}{|c|c|c|c|c|c|c|c|}
\hline & Never nGOR & Former nGOR & p-value ${ }^{\#}$ & New nGOR & p-value ${ }^{\#}$ & Persistent nGOR & p-value ${ }^{\#}$ \\
\hline Subjects $\mathbf{n}$ & 1298 & 139 & & 201 & & 123 & \\
\hline Wheeze and breathlessness & 6.0 & 7.3 & 0.57 & 9.9 & 0.06 & 16.0 & $<0.001$ \\
\hline Wheeze and no cold & 7.8 & 5.0 & 0.31 & 12.2 & 0.06 & 15.7 & 0.01 \\
\hline Nocturnal chest tightness & 7.5 & 8.2 & 0.81 & 11.2 & 0.11 & 17.1 & 0.003 \\
\hline $\begin{array}{c}\text { Nocturnal attacks of } \\
\text { breathlessness }\end{array}$ & 3.1 & 4.8 & 0.31 & 6.4 & 0.03 & 7.4 & 0.03 \\
\hline Nocturnal cough & 19.5 & 22.6 & 0.56 & 23.1 & 0.35 & 36.1 & 0.001 \\
\hline New-onset asthma & 5.4 & 7.3 & 0.41 & 8.5 & 0.11 & 13.0 & 0.002 \\
\hline Any respiratory symptom & 49.0 & 65.1 & 0.02 & 60.0 & 0.02 & 79.2 & $<0.001$ \\
\hline
\end{tabular}

Data are presented as \%, unless otherwise stated. ": calculated with "never nGOR" as a reference group. Bold represents statistical significance.

mean \pm SD age $(33.7 \pm 7.2$ years versus $32.7 \pm 6.9$ years; $p<0.001)$. No difference was found regarding sex or BMI between participants and nonparticipants.

\section{DISCUSSION}

This prospective follow-up study shows that subjects with persistent nGOR were approximately two times more likely to report an onset of asthma and respiratory symptoms at followup after 9 years compared with participants who never had nGOR. Symptoms of OSA were also much more likely to occur during the study period among subjects with new onset or persistent nGOR. The association between new nGOR and new OSA symptoms was stronger among males than females, but the association between persistent nGOR and new respiratory symptoms was stronger among females than males.

The present study suggests that nGOR is a risk factor for developing asthma. However, we did not find a significant

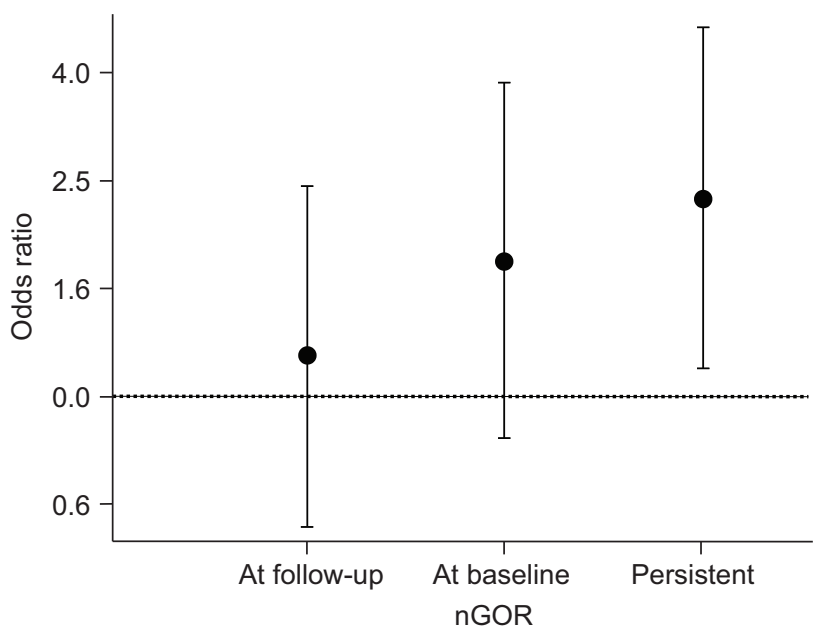

FIGURE 2. Odds ratios and $95 \%$ confidence intervals for the association between new-onset asthma and nocturnal gastro-oesophageal reflux (nGOR), adjusted for sex, age, location, smoking history at follow-up, body mass index (BMI) at baseline and change in BMI (never nGOR were used as a reference group). effect of nGOR treatment on the study outcomes, except for a lesser decrease in FVC among new nGOR subjects who were on treatment compared with those without treatment. The reason for the lack of association to nGOR treatment may be due to the fact that our data collection on nGOR treatment did not differ between the type of medication used, the dosage or total treatment time. Therefore, all participants who had used any GOR medication in the preceding month of any frequency were classified as having nGOR treatment, making the nGOR treatment group rather diffuse. Some studies, but not all, have reported that GOR treatment with proton pump inhibitors

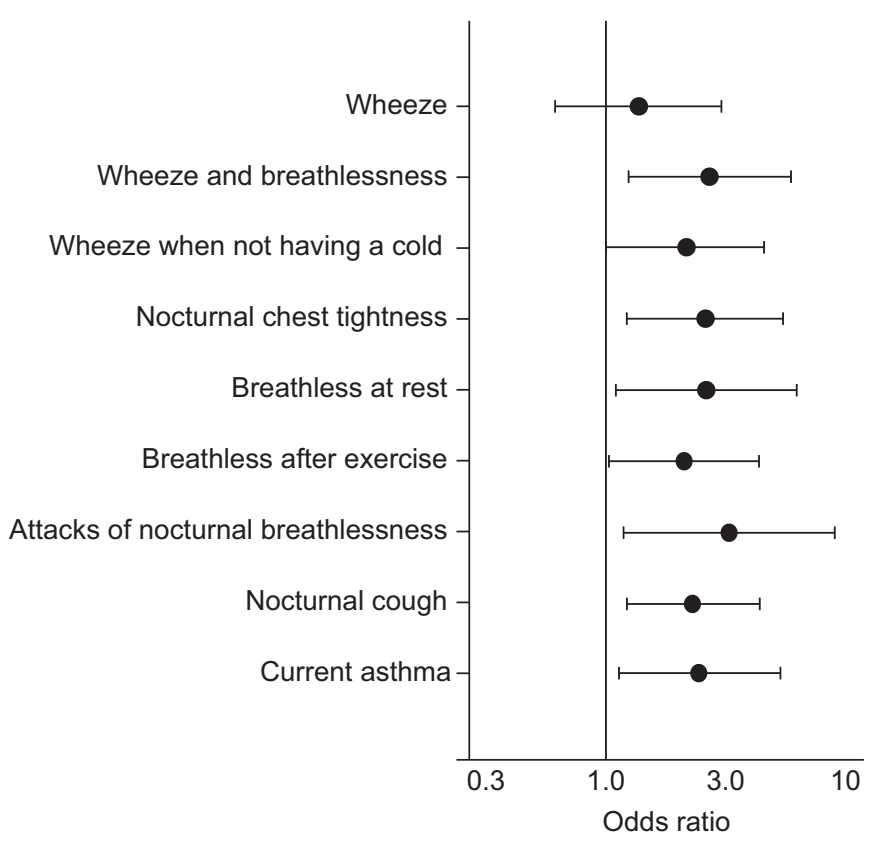

FIGURE 3. Odds ratios and $95 \%$ confidence intervals for the association between new-onset of respiratory symptoms and persistent nocturnal gastrooesophageal reflux (nGOR) compared with never nGOR, adjusted for sex, age, location, smoking history at follow-up, body mass index (BMI) at baseline and change in BMI. 
TABLE 3 Multiple logistic regression for the associations between any respiratory symptom or any obstructive sleep apnoea (OSA) symptom and independent variables, adjusted for location

\begin{tabular}{|c|c|c|c|c|}
\hline & Any respiratory symptom & p-value & Any OSA symptom & $\mathrm{p}$-value \\
\hline Never nGOR & 1 & & 1 & \\
\hline New nGOR & $1.6(1.0-2.5)$ & 0.06 & $2.2(1.3-3.6)$ & 0.003 \\
\hline Persistent nGOR & $3.0(1.6-5.6)$ & $<0.001$ & $2.0(1.0-3.7)$ & 0.04 \\
\hline Change in BMI per $\mathrm{kg} \cdot \mathrm{m}^{-2}$ & $1.1(1.0-1.1)$ & 0.09 & $1.1(1.0-1.2)$ & 0.01 \\
\hline Never-smoker & 1 & & 1 & \\
\hline Ex-smoker & $1.2(0.9-1.8)$ & 0.26 & $1.1(0.7-1.6)$ & 0.63 \\
\hline Quitter & $1.8(1.1-2.9)$ & 0.02 & $1.2(0.7-1.9)$ & 0.48 \\
\hline Smoker & $3.7(2.5-5.5)$ & $<0.001$ & $1.7(1.1-2.5)$ & 0.01 \\
\hline Baseline BMI per $\mathrm{kg} \cdot \mathrm{m}^{-2}$ & $1.1(1.0-1.1)$ & 0.03 & $1.0(1.0-1.1)$ & 0.17 \\
\hline
\end{tabular}

Data are presented as adjusted OR $(95 \% \mathrm{Cl})$, unless otherwsie stated. nGOR: nocturnal gastro-oesophageal reflux, BMI: body mass index. Bold represents statistical significance.

(PPIs) improves asthma-related quality of life and may even improve respiratory function $[6-8,21]$. These effects have mostly been minor, which has led some to conclude that GOR is not a major trigger for asthma [22]. However, our results indicate that the new onset of asthma is more than twofold among those with prevalent nGOR compared with those without nGOR, even after adjusting for common confounding factors. We, therefore, hypothesise that the modest effects of GOR treatment on asthma might rather be explained by a relative irreversibility of GOR-induced airway damage. Indeed, as many have pointed out, PPIs do not stop reflux but rather make it less acidic, and can thereby only limit but not eliminate the potential damage to the airways. Additionally, those with more severe GOR are usually excluded from these treatment studies [6]. When all of the above is taken into consideration, it must be considered possible that nGOR can be implicated in the pathogenesis of asthma in a subgroup of patients.
Subjects with persistent nGOR were roughly twice as likely to develop any respiratory symptoms under the study period as those without nGOR, even after adjusting for confounding factors. This is in accordance with other studies that report associations between GOR and chronic cough, asthma and various upper respiratory tract symptoms [3, 23, 24]. Two mechanisms have mainly been proposed in this context. First, microaspiration of gastric acid can cause bronchoconstriction, thereby predisposing to respiratory symptoms and asthma. Secondly, bronchospasm can be caused by a vagal reflex that is triggered by gastric acid in the distal oesophagus [25]. The present results add prospective data to these known associations, thereby strengthening theories on causality in these associations.

We found that nGOR increases the risk of developing symptoms of OSA, supporting the conclusion that nGOR may play a role in the genesis of OSA. Even though we found

\begin{tabular}{|c|c|c|c|c|c|c|c|c|}
\hline & Never nGOR & Former nGOR & p-value ${ }^{\#}$ & New nGOR & p-value $\#$ & Persistent nGOR & p-value ${ }^{\#}$ & p-value \\
\hline Subjects $\mathrm{n}$ & 1298 & 139 & & 201 & & 123 & & \\
\hline New observed snoring & 19.9 & 20.2 & 0.95 & 24.7 & 0.16 & 25.6 & 0.22 & 0.09 \\
\hline New observed apnoeas & 2.7 & 6.8 & 0.01 & 7.3 & 0.002 & 10.6 & $<0.001$ & $<0.001$ \\
\hline $\begin{array}{l}\text { New snoring and/or apnoea } \\
\text { with new daytime } \\
\text { sleepiness }\end{array}$ & 6.8 & 11.1 & 0.29 & 14.1 & 0.03 & 17.1 & 0.03 & 0.003 \\
\hline $\begin{array}{l}\text { Epworth sleepiness scale at } \\
\text { follow-up }\end{array}$ & $6.1 \pm 3.7$ & $6.5 \pm 4.1$ & 0.33 & $7.6 \pm 4.1$ & $<0.001$ & $8.1 \pm 4.4$ & $<0.001$ & $<0.001$ \\
\hline
\end{tabular}

Data are presented as mean \pm SD or \%, unless otherwise stated. \#: calculated with "never nGOR" as a reference group; ": test for trend. Bold represents statistical significance. 


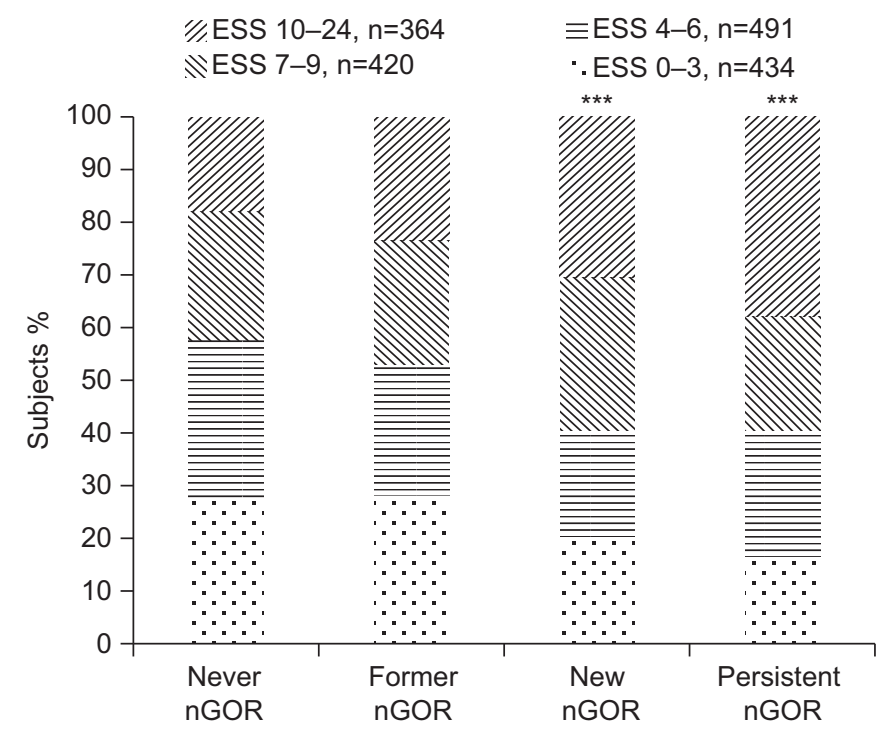

FIGURE 4. Epworth Sleepiness Scale score between nocturnal gastrooesophageal reflux (nGOR) groups. ${ }^{* \star}: \mathrm{p}<0.001$ (Chi-squared test, compared with never nGOR).

increase in BMI also to be a risk factor for the development of symptoms of OSA, the association with nGOR was independent of changes in BMI. Also, since the prevalence of OSA increases with age, especially in the age groups studied during this 9-year prospective study, the confounding effects of ageing predisposing to OSA must be considered. As the new onset of OSA symptoms was twice as common in the nGOR groups compared with those without nGOR, even after adjusting for age, ageing alone cannot explain the increase in OSA symptoms in the nGOR groups. Therefore, an independent effect of nGOR on causation of OSA must be considered. This is in agreement with results from another epidemiological study on the association between nGOR and symptoms of OSA [24]. As OSA is caused by upper airway narrowing and recurrent, intermittent upper airway collapse [26], oedema in the upper airway caused by nGOR has been hypothesised to play a role in the OSA pathogenesis, but this remains to be studied further [27].

Other studies report that OSA might induce nGOR, as reflux is more common among OSA patients and treatment of OSA with continuous positive airway pressure effectively diminishes nGOR symptoms [28]. A few mechanisms have been suggested in support of a causal relationship. Contrary to former belief, nocturnal reflux is not caused by negative intrathoracic pressure during apnoeic episodes, as recent studies have reported the lower oesophageal sphincter contracts during apnoeic episodes and thereby inhibits gastric acid reflux [29-31]. Rather, nGOR is more likely caused by transient lower oesophageal sphincter relaxation (TLESR) [30]. These TLESRs are more common in OSA patients than in a normal population and could explain the relationship between OSA and nGOR. In agreement with SHEPHERD et al. [31], we hypothesise that the repeated stress of negative intrathoracic pressure in OSA patients on the lower oesophageal sphincter may strain it to the point where it starts losing its tonus intermittently and thereby generates more TLESRs.

The key strengths of this study were the prospective nature of the study, the high number of participants and the acceptable response rate. Even so, a few methodological issues need to be discussed. First, our definition of the nGOR groups was based on self-reported heartburn, marked as "less than once a week" or more frequently, without any objective diagnostic tests. This might have led to an overrepresentation of nGOR among the participants, thereby reducing the possible effects of nGOR on the outcomes, but also served to increase the power in the statistical analyses. Therefore, we also ran all the calculations with nGOR defined as heartburn at least once a week or more frequently, which is considered reasonably specific [32, 33]. Based on this definition, the group with persistent nGOR group consisted of 34 subjects. In all aspects, the results were very similar to those reported above, although sometimes not reaching the same statistical significance as for the nGOR groups we use (data not shown). We, therefore, conclude that the wide definition of nGOR used in our research did not

TABLE 5 Lung function in relation to nocturnal gastro-oesophageal reflux (nGOR)

\begin{tabular}{|c|c|c|c|c|c|c|c|}
\hline & $\begin{array}{l}\text { Never } \\
\text { nGOR }\end{array}$ & $\begin{array}{l}\text { Former } \\
\text { nGOR }\end{array}$ & p-value ${ }^{\#}$ & $\begin{array}{c}\text { New } \\
\text { nGOR }\end{array}$ & p-value ${ }^{\#}$ & $\begin{array}{c}\text { Persistent } \\
\text { nGOR }\end{array}$ & p-value ${ }^{\#}$ \\
\hline Subjects $n$ & 1298 & 139 & & 201 & & 123 & \\
\hline \multicolumn{8}{|l|}{ Change per year in $\%$ pred } \\
\hline FEV1 & $-0.22 \pm 0.89$ & $-0.34 \pm 0.97$ & 0.18 & $-0.24 \pm 1.01$ & 0.78 & $-0.26 \pm 0.82$ & 0.68 \\
\hline FVC & $-0.08 \pm 1.02$ & $-0.15 \pm 0.88$ & 0.47 & $-0.16 \pm 1.23$ & 0.37 & $-0.08 \pm 0.96$ & 0.98 \\
\hline $\mathrm{FEV}_{1} / \mathrm{FVC}$ & $0.000 \pm 0.007$ & $-0.001 \pm 0.005$ & 0.38 & $0.000(0.007$ & 0.26 & $-0.001 \pm 0.007$ & 0.60 \\
\hline New COPD (GOLD stage 1-4) & 2.4 & 1.8 & 0.73 & 3.9 & 0.27 & 1.0 & 0.39 \\
\hline $\begin{array}{l}\text { New bronchial } \\
\text { hyperreactivity }\end{array}$ & 7.0 & 7.3 & 0.93 & 5.9 & 0.71 & 14.8 & 0.04 \\
\hline Slope change & $-0.03 \pm 0.28$ & $0.002 \pm 0.26$ & 0.45 & $-0.01 \pm 0.28$ & 0.61 & $0.03 \pm 0.30$ & 0.15 \\
\hline
\end{tabular}


confound the results of our study. Secondly, the data on OSA were only subjective, as we were not able to collect objective data, for example, by performing a polysomnography on this large group of participants. Thirdly, the use of questionnaires translated in each country from the original English carries the risk of a translation bias. However, we consider this risk to be small, as the questions were all checked via back-translation and tested for translation bias. The questions regarding nGOR were based on a former, thoroughly validated questionnaire [3]. Finally, since many variables were studied in this research, the risk of a type I error must be considered. However, as there was a common trend in the results, where the symptom prevalence increased between the study groups similarly for various symptoms, the risk of a type I error must be considered to be small.

In conclusion, persistent nGOR contributes to the development of asthma and respiratory symptoms. The risk of new onset of OSA symptoms is also higher among subjects with nGOR. These findings further support the conclusion that nGOR may play a role in the genesis of respiratory symptoms and diseases.

\section{SUPPORT STATEMENT}

The study was supported financially by the Swedish Heart and Lung foundation, the Swedish Asthma and Allergy Association, the Vårdal Foundation for Health Care Science and Allergy Research, the Icelandic Research Council (2013), the Landspitali University Hospital Fund (2010-2012), and the Research Foundation of Flanders, Belgium.

\section{STATEMENT OF INTEREST}

Conflict of interest information can be found alongside the online version of this article at www.erj.ersjournals.com

\section{ACKNOWLEDGEMENTS}

The authors thank all the participants in the study.

\section{REFERENCES}

1 Moayyedi P, Talley NJ. Gastro-oesophageal reflux disease. Lancet 2006; 367: 2086-2100.

2 Tattersfield AE, Knox AJ, Britton JR, et al. Asthma. Lancet 2002; 360: 1313-1322.

3 Gislason T, Janson C, Vermeire P, et al. Respiratory symptoms and nocturnal gastroesophageal reflux: A population-based study of young adults in three European countries. Chest 2002; 121: 158-163.

4 Sontag SJ. Gastroesophageal reflux disease and asthma. J Clin Gastroenterol 2000; 30: S9-S30.

5 Mise K, Capkun V, Jurcev-Savicevic A, et al. The influence of gastroesophageal reflux in the lung: a case-control study. Respirology 2010; 15: 837-842.

6 Kiljander TO, Junghard O, Beckman O, et al. Effect of esomeprazole $40 \mathrm{mg}$ once or twice daily on asthma: a randomized, placebo-controlled study. Am J Respir Crit Care Med 2010; 181: 1042-1048.

7 Coughlan JL, Gibson PG, Henry RL. Medical treatment for reflux oesophagitis does not consistently improve asthma control: A systematic review. Thorax 2001; 56: 198-204.

8 Mastronarde JG, Anthonisen NR, Castro M, et al. Efficacy of esomeprazole for treatment of poorly controlled asthma. N Engl J Med 2009; 360: 1487-1499.

9 des Varannes SB, Errieau G, Tessier C. Deux tiers des malades ayant un reflux gastro-œsophagien ont des symptômes nocturnes: enquête réalisée par 562 médecins auprès de 36663 patients [Two thirds of patients with gastroesophageal reflux have nocturnal symptoms - survey by 562 general practitioners of 36663 patients]. Presse Medicale 2007; 36: 591-597.

10 Orr W. Sleep-related gastro-oesophageal reflux as a distinct clinical entity. Aliment Pharmacol Therapeut 2010; 31: 47-56.

11 Demeter P, Visy KV, Magyar P. Correlation between severity of endoscopic findings and apnea-hypopnea index in patients with gastroesophageal reflux disease and obstructive sleep apnea. World J Gastroenterol 2005; 11: 839-841.

12 Jansson C, Nordenstedt H, Wallander MA, et al. A population-based study showing an association between gastroesophageal reflux disease and sleep problems. Clin Gastroenterol Hepatol 2009; 7: 960-965.

13 Janson C, De Backer W, Gislason T, et al. Increased prevalence of sleep disturbances and daytime sleepiness in subjects with bronchial asthma: a population study of young adults in three European countries. Eur Respir J 1996; 9: 2132-2138.

14 Janson C, de Marco R, Accordini S, et al. Changes in the use of antiasthmatic medication in an international cohort. Eur Respir J 2005; 26: 1047-1055.

15 Gunnbjornsdottir MI, Omenaas E, Gislason T, et al. Obesity and nocturnal gastro-oesophageal reflux are related to onset of asthma and respiratory symptoms. Eur Respir J 2004; 24: 116-121.

16 Benediktsdottir B, Janson C, Lindberg E, et al. Prevalence of restless legs syndrome among adults in Iceland and Sweden: lung function, comorbidity, ferritin, biomarkers and quality of life. Sleep Med 2010; 11: 1043-1048.

17 Chinn S, Jarvis D, Melotti R, et al. Smoking cessation, lung function, and weight gain: a follow-up study. Lancet 2005; 365: 1629-1635.

18 Quanjer PH, Tammeling GJ, Cotes JE, et al. Lung volumes and forced ventilatory flows. Report Working Party Standardization of Lung Function Tests, European Community for Steel and Coal. Official Statement of the European Respiratory Society. Eur Respir J 1993; 16: Suppl. 16, 5-40.

19 Chinn S, Jarvis D, Luczynska CM, et al. An increase in bronchial responsiveness is associated with continuing or restarting smoking. Am J Respir Crit Care Med 2005; 172: 956-961.

20 Shaaban R, Leynaert B, Soussan D, et al. Physical activity and bronchial hyperresponsiveness: European Community Respiratory Health Survey II. Thorax 2007; 62: 403-410.

21 Holbrook JT, Wise RA, Gold BD, et al. Lansoprazole for children with poorly controlled asthma: a randomized controlled trial. Jama 2012; 307: 373-381.

22 Gibson PG, Henry RL, Coughlan JL. Gastro-oesophageal reflux treatment for asthma in adults and children. Cochrane Database Syst Rev 2003; CD001496.

23 Fontana GA, Pistolesi M. Cough. 3: chronic cough and gastrooesophageal reflux. Thorax 2003; 58: 1092-1095.

24 Emilsson OI, Janson C, Benediktsdottir B, et al. Nocturnal gastroesophageal reflux, lung function and symptoms of obstructive sleep apnea: results from an epidemiological survey. Respir Med 2012; 459-466.

25 Harding SM. Gastroesophageal reflux, asthma, and mechanisms of interaction. Am J Med 2001; 111: Suppl. 8A, 8S-12S.

26 Owens RL, Eckert DJ, Yeh SY, et al. Upper airway function in the pathogenesis of obstructive sleep apnea: a review of the current literature. Curr Opin Pulm Med 2008; 14: 519-524.

27 Orr WC, Robert JJ, Houck JR, et al. The effect of acid suppression on upper airway anatomy and obstruction in patients with sleep apnea and gastroesophageal reflux disease. J Clin Sleep Med 2009; 5: 330-334.

28 Green BT, Broughton WA, O'Connor JB. Marked improvement in nocturnal gastroesophageal reflux in a large cohort of patients with obstructive sleep apnea treated with continuous positive airway pressure. Arch Intern Med 2003; 163: 41-45.

29 Berg S, Hoffstein V, Gislason T. Acidification of distal esophagus and sleep-related breathing disturbances. Chest 2004; 125: 2101-2106. 
30 Kuribayashi S, Kusano M, Kawamura O, et al. Mechanism of gastroesophageal reflux in patients with obstructive sleep apnea syndrome. Neurogastroenterol Motil 2010; 22: e611-e172.

31 Shepherd K, Hillman D, Holloway R, et al. Mechanisms of nocturnal gastroesophageal reflux events in obstructive sleep apnea. Sleep Breath 2010; 101: 350-357.
32 Dent J, El-Serag HB, Wallander MA, et al. Epidemiology of gastrooesophageal reflux disease: a systematic review. Gut 2005; 54: 710-717.

33 Vakil N, van Zanten SV, Kahrilas P, et al. The Montreal definition and classification of gastroesophageal reflux disease: a global evidence-based consensus. Am J Gastroenterol 2006; 101: 1900-1920. 